\title{
The association of breakfast skipping and television viewing at breakfast with weight status among parents of 10-12-year-olds in eight European countries; the ENERGY (EuropeaN Energy balance Research to prevent excessive weight Gain among Youth) cross-sectional study
}

\author{
Helga Birgit Bjørnarå ${ }^{1}$, Frøydis N Vik ${ }^{1, *}$, Johannes Brug ${ }^{2}$, Yannis Manios ${ }^{3}$, \\ Ilse De Bourdeaudhuij ${ }^{4}$, Natasa Jan ${ }^{5}$, Lea Maes 6 , Luis A Moreno7, \\ Alain Dössegger ${ }^{8}$ and Elling Bere ${ }^{1}$ \\ 'Department of Public Health, Sport and Nutrition, University of Agder, PO Box 422, 4604 Kristiansand, \\ Norway: ${ }^{2} E M G O$ Institute for Health and Care Research and the Department of Epidemiology and Biostatistics, \\ VU University Medical Center, Amsterdam, The Netherlands: ${ }^{3}$ Department of Nutrition and Dietetics, Harokopio \\ University, Athens, Greece: ${ }^{4}$ Department of Movement and Sport Sciences, Ghent University, Ghent, Belgium: \\ ${ }^{5}$ Slovenian Heart Foundation, Ljubljana, Slovenia: ${ }^{6}$ Department of Public Health, Ghent University, Ghent, \\ Belgium: ${ }^{7}$ GENUD (Growth, Exercise, Nutrition and Development) Research Group, EU Ciencias de la Salud, \\ Universidad de Zaragoza, Zaragoza, Spain: ${ }^{8}$ The Federal Institute of Sport, Magglingen, Switzerland
}

Submitted 21 May 2012: Final revision received 20 December 2012: Accepted 5 February 2013: First published online 11 March 2013

\begin{abstract}
Objective: The main objective was to assess the relationship of breakfast skipping, television (TV) viewing at breakfast and breakfast without TV with weight status among parents of 10-12-year-olds in eight European countries.

Design: A cross-sectional survey assessed breakfast eating and TV viewing at breakfast by three frequency questions and parents were categorized into: (i) breakfast skippers; (ii) breakfast with TV (TV watchers at breakfast); and (iii) breakfast without TV (breakfast eaters who do not watch TV during breakfast). Self-reported weight and height were used to categorize weight status as underweight, normal weight, overweight and obese. Multinomial logistic regression analyses were conducted with weight status as the dependent variable and breakfast habits as predictors, adjusting for sex, ethnicity and level of education. Setting: The survey was conducted in 2010 in 199 primary schools across eight European countries participating in the ENERGY (EuropeaN Energy balance Research to prevent excessive weight Gain among Youth) cross-sectional study. Subjects: Parents ( $n$ 6512) of 10-12-year-olds responded to the questionnaire.

Results: In the total study sample, with breakfast without TV as the reference group and adjusting for sex, ethnicity and level of education, the OR of being respectively overweight or obese (compared with normal weight) was $1 \cdot 2$ (95\% CI $1 \cdot 0,1 \cdot 4)$ or $1 \cdot 8(95 \%$ CI $1 \cdot 5,2 \cdot 3)$ for breakfast skippers. The OR of being respectively underweight or obese was $0.5(95 \% \mathrm{CI} 0 \cdot 2,0 \cdot 9)$ or $1.4(95 \% \mathrm{CI} 1 \cdot 1$, 1.8) for breakfast with TV.

Conclusions: Breakfast skippers were significantly more likely to be overweight and obese, and those eating breakfast while watching TV were significantly more likely to be obese and less likely to be underweight.
\end{abstract}

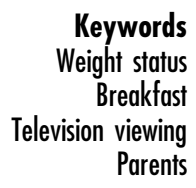

According to the WHO, obesity is one of today's most pressing public health burdens, due to its increasing prevalence and related chronic illnesses ${ }^{(1)}$. In terms of the lack of effective long-term obesity treatment, and the fact that the ill-health effects of obesity are not fully reversible, obesity prevention should be emphasized ${ }^{(2)}$. Adiposity is the result of a positive energy balance over time ${ }^{(3)}$, caused mainly by modifiable energy balance-related behaviours $(\mathrm{EBRB})^{(4)}$. Specific EBRB are associated with overweight and obesity, including breakfast skipping and television viewing ${ }^{(5)}$. Disparities in these EBRB, as well as other health behaviours, are observed according to sex, ethnicity and socio-economic status (SES) ${ }^{(6-9)}$ and tend to be generally consistent with reported disparities in obesity ${ }^{(10-12)}$. 
Several studies have found an inverse association between breakfast consumption and obesity, both crosssectionally $^{(13,14)}$ and longitudinally ${ }^{(15,16)}$. Huang et al. reported that the OR of being obese was 1.34 (95\% CI $1 \cdot 15,1 \cdot 56$ ) for breakfast skippers compared with breakfast eaters among Taiwan adults, when controlling for several potential confounders ${ }^{(14)}$. Merten et al. found that regular breakfast consumption (eating breakfast on $4 \mathrm{~d}$ / week or more) during both adolescence and young adulthood seemed to reduce the risk for adult obesity ${ }^{(15)}$. Further, a US prospective study reported increased breakfast skipping from adolescence into young adulthood to be associated with increased weight gain during the transition $^{(16)}$. Breakfast content is likely to affect physiological responses like satiety, glycaemia ${ }^{(17)}$ and the thermic effect of food ${ }^{(3)}$, but could also represent an overall healthy $\operatorname{diet}^{(18)}$ and a generally beneficial lifestyle ${ }^{(19)}$. Thus the causality between breakfast skipping and obesity risk needs further investigation.

Numerous cross-sectional and longitudinal studies have reported a general consistent relationship between time spent watching television (TV) and obesity risk in adults $^{(20-22)}$. Among proposed reasons for this association are reduced engagement in light-intensity activities and thus decreased energy expenditure ${ }^{(23)}$, more frequent meals regardless of hunger ${ }^{(24)}$, increased intakes of snacks ${ }^{(7)}$ and high-density foods when eating in front of the $\mathrm{TV}^{(25)}$ and an overall poorer dietary quality ${ }^{(26)}$. The association between TV viewing and unfavourable nutrition is suggested to be mediated by exposure to advertising of energy-rich and nutrient-poor foods and beverages ${ }^{(27,28)}$, as well as individual characteristics like memory for advertisements and distractibility $^{(29)}$. There might also be a link between high TV viewing and an unhealthy lifestyle in general, in terms of both engagement in other sedentary activities ${ }^{(30)}$ and unfavourable eating and drinking patterns ${ }^{(31)}$.

Observational studies on children have found positive associations between prevalence of TV viewing during meals and both higher mean BMI and poorer dietary quality $^{(32,33)}$. Few observational studies have been conducted on the implications of TV viewing during meals in adults. However, three experimental studies manipulating this condition all reported enhanced dietary intake, regardless of rated appetite, when meals were consumed while watching TV among both men and women with varying weight status $^{(25,34,35)}$. Another experimental study found that watching TV during lunch enhanced afternoon snack intake in young women, suggesting that the effects of TV viewing on food intake extend beyond the time of actual watching ${ }^{(36)}$.

Few cross-European studies have been conducted on the relationships of breakfast skipping, breakfast with TV and breakfast without TV with weight status among adults. The objective of the present study was to assess these associations in eight European countries among the parents participating in the EuropeaN Energy balance Research to prevent excessive weight Gain among Youth
(ENERGY) study. Additional aims were to assess potential country differences as well as potential inequalities regarding sex, ethnicity and education (as an indicator of SES) in terms of prevalence of skipping breakfast and watching TV during breakfast.

\section{Methods}

The ENERGY project includes a cross-sectional, schoolbased survey of overweight, obesity and EBRB across eight European countries. The conceptual design of the entire project ${ }^{(37)}$, as well as a description of the crosssectional survey ${ }^{(4)}$, have been previously published. The present study was conducted according to the guidelines laid down in Declaration of Helsinki and all procedures involving human subjects were approved by the relevant ethical committees and ministries ${ }^{(4)}$ (in Belgium, the Medical Ethics Committee of the University Hospital Ghent; in Greece, the Bioethics Committee of Harokopio University; in Hungary, the Scientific and Ethics Committee of the Health Sciences Council; in the Netherlands: the Medical Ethics Committee of the VU University Medical Center; in Norway, the National Committees for Research Ethics in Norway; in Slovenia, the National Medical Ethics Committee of the Republic of Slovenia; in Spain, the Clinical Research Ethics Committee of the Government of Aragón; and in Switzerland, the Ethical Committee Basel, the Ethical Committee St. Gallen, the Ethical Committee Aargau and the Ethical Committee Bern).

\section{Sample and procedure}

Seven countries were included in the school-based survey (Belgium, Greece, Hungary, the Netherlands, Norway, Slovenia and Spain) conducted between March and July 2010. Switzerland started its survey in May and distributed the last questionnaires in December. A national sample frame was used in Greece, Hungary, the Netherlands and Slovenia, while schools from specific regions were sampled in Spain, Belgium, Norway and Switzerland. Students in their final year of primary school (aged 10 to 12 years), and one of their parents, were included in the study. The sample size was calculated to detect differences in children's overweight prevalence between countries. Based on previous cross-European studies, a minimum sample of 1000 schoolchildren per country, and one parent (the main caregiver) for each child, was aimed for.

Within each country or region, three provinces were randomly selected from each of the lowest, mid and highest tertiles of degree of urbanization (i.e. the percentage of inhabitants living in municipalities of $>20000$ persons). A municipality of $>20000$ inhabitants from each selected province was randomly chosen, with schools randomly selected for inclusion in the study from all schools in that municipality. The clustering of the survey was taken into account in sample size calculations. 
A school recruitment letter was sent to the headmaster of the sampled schools, followed by a personal telephone call. Following the schools' agreement, parents received a letter explaining the study purpose and were asked for written consent for their child's participation in countries where active informed consent (opt in) was required (Hungary, Norway, Spain and Switzerland) or were provided with a form to declare that their child was not to be included in the study in the other countries where medical ethical approval required passive informed consent (opt out). Children participating in the study confidentially completed the child questionnaire during one school hour in the presence of a trained research assistant or project worker, and received a parent questionnaire in a closed envelope to take home for completion by one of their parents. Completed parent questionnaires were brought back to the school by the children and were collected by the teacher. There were no incentives for filling in the questionnaires for either the children or the parents. A total of 199 schools participated, with 7915 children and 6512 parent questionnaires completed (response rate 55\%). The 6512 parents constitute the study sample in the present study.

\section{Measures}

All measures were obtained using standardized protocols across the countries. Consistency of questionnaires was further ensured by translating the original questionnaire (developed in English) into each relevant language and then back-translating into English. Only parts of the parent questionnaire will be used in the present study; further details about the questionnaire and other measures are described elsewhere ${ }^{(4)}$.

\section{Parent questionnaire}

The selection of EBRB and correlates measured in the questionnaires were based on the results of literature reviews and secondary data analyses conducted with children as the target population, in the earlier stages of the ENERGY project ${ }^{(37)}$. Self-reported levels of specific parental EBRB as well as personal and family environmental variables were assessed ${ }^{(4)}$. The parent questionnaire was first pre-tested among small samples in all participating countries to assess the parents' general opinion about the questionnaire, the comprehensibility and feasibility of the questionnaire and their opinion about its design. In addition, test-retest reliability and construct validity of the parent questionnaire was tested, and details are described elsewhere ${ }^{(38)}$.

\section{Personal variables}

Weight, height, sex, educational level and ethnicity were all self-reported in the parent questionnaire. Parent BMI was computed from height and weight and further collapsed into a new variable with four categories: underweight (coded $0 ;$ BMI $<18.5 \mathrm{~kg} / \mathrm{m}^{2}$ ), normal weight (coded 1 ;
BMI $\geq 18.5$ to $\left.\leq 24.9 \mathrm{~kg} / \mathrm{m}^{2}\right)$, overweight (coded $2 ;$ BMI $\geq$ 25.0 to $\leq 29 \cdot 9 \mathrm{~kg} / \mathrm{m}^{2}$ ) and obese (coded 3; BMI $\geq$ $30 \cdot 0 \mathrm{~kg} / \mathrm{m}^{2}$ ). SES was assessed as 'How many years of school education did you/your partner complete?' The response options were 'less than 7 years', '7-9 years', '10-11 years', '12-13 years', '14 years or more'. Parental education was dichotomized into low (coded 0; both parents/caregivers with fewer than 14 years of education) and high (coded 1; at least one parent/caregiver with 14 or more years of education), which in this international data set approximately distinguishes families with at least one caregiver who has completed medium or higher vocational, college or university training from other families. Ethnicity was assessed by asking 'Were the biological parents of your child born in [partner country]?', with three response alternatives: 'yes', 'no, only one parent' or 'no, none of the parents'. According to the definition of foreign ethnic background used by Statistics Netherlands ${ }^{(39)}$, parental ethnicity was dichotomized into non-native [partner country] (coded 0; none or one of the parents born in [partner country]) and native [partner country] (coded 1; both of the parents born in [partner country]).

\section{Breakfast eating and television viewing while eating breakfast}

Prevalence of breakfast eating was assessed by asking two frequency questions distinguishing weekdays and weekends: (i) 'From Monday to Friday, how many days do you usually eat breakfast?', with six response alternatives ranging from 'I never eat breakfast on weekdays' to ' 5 days'; and (ii) 'How many times do you usually eat breakfast on the weekend?', with three response alternatives of 'I never eat breakfast on the weekends', 'I usually eat breakfast on 1 day (Saturday OR Sunday)' or 'I usually eat breakfast on both days (Saturday AND Sunday)'. Breakfast frequency per week was calculated by adding up the answers to the two questions. The frequency score was re-coded into a skipping breakfast score (breakfast on $7 \mathrm{~d} /$ week, coded 0 ; and breakfast on 0-6d/week, coded 1). Prevalence of TV viewing while eating breakfast was assessed with one item: 'In general, how often do you watch television during breakfast?', with five response options of 'always', 'often', 'sometimes', 'not often' or 'never'. The frequency score was dichotomized into not watching TV (coded 0; those who 'never' watch TV during breakfast) and watching TV (coded 1; those who watch TV during breakfast, ranging from 'not often' to 'always'). Based on the 'skipping breakfast' variable and the 'TV during breakfast' variable, a new variable coded 1-3 was created: breakfast skippers (coded 1), breakfast with TV (coded 2; containing only those reporting to eat breakfast every day) and breakfast without TV (coded 3; containing only those eating breakfast every day). Test-retest reliability of the items measuring these selected behaviours appeared to be good to excellent for the total study sample, in a separate 
test-retest and construct validity study, as expressed by the intra-class correlation coefficient (ICC) and percentage agreement ${ }^{(38)}$. For the question 'From Monday to Friday, how many days do you usually eat breakfast?', ICC was 0.87 with $90 \%$ agreement. For the question 'How many times do you usually eat breakfast on the weekend?', ICC was 0.85 with $92 \%$ agreement. For the item 'In general, how often do you watch television during breakfast?', ICC was 0.74 with $83 \%$ agreement $^{(38)}$.

\section{Statistical methods}

All data were analysed using the statistical software package SPSS version 18. Descriptive analysis and oneway ANOVA were performed to calculate proportions classified as underweight, normal weight, overweight and obese, according to sex, ethnicity, level of education and country, as well as the proportions categorized as breakfast skippers, breakfast with TV and breakfast without TV, according to weight status, sex, ethnicity, level of education and country (Table 1). Multinomial logistic regression analyses were conducted to calculate odds ratios on the relationship between weight status and breakfast skipping and breakfast with TV, with breakfast without TV as reference group, in the total sample and for each country separately, adjusting for sex, ethnicity and level of education as potential confounding factors (Table 2). Multinomial logistic regression analyses were further performed to assess potential inequalities regarding sex, ethnicity and level of education in terms of respectively skipping breakfast and breakfast with TV compared with breakfast without TV, in the total sample and for each country separately (Table 3). Analyses with sub-populations with fewer than five observations (e.g. $<5$ underweight breakfast skippers in the Norwegian data) were classified as non-applicable (NA) with regard to the validity of the analysis ${ }^{(40)}$.

\section{Results}

The study sample included 6512 parents with the mean age of 41 years; $83 \%$ females, $65 \%$ high SES and $83 \%$ natives. Further, $32 \%$ were categorized as breakfast skippers, $23 \%$ as breakfast with TV and $44 \%$ as breakfast without TV (Table 1). The proportion categorized into the different breakfast habits ranged greatly between the eight European countries; breakfast skippers ranged from $12 \%$ in the Netherlands to $54 \%$ in Greece $(P \leq 0 \cdot 001)$, breakfast with TV ranged from $4 \%$ in Switzerland to $78 \%$ in Spain ( $P \leq 0.001)$ while breakfast without TV ranged from $5 \%$ in Spain to $72 \%$ in Belgium $(P \leq 0 \cdot 001)$.

Adjusting for sex, ethnicity and parental education as potential confounders, the OR of being overweight was $1 \cdot 2(95 \%$ CI $1 \cdot 0,1 \cdot 4)$ for breakfast skippers $v$. breakfast without TV (Table 2), the OR of being obese was

Table 1 Descriptive analysis of the proportions classified as underweight, normal weight, overweight and obese, as well as breakfast skippers, breakfast with TV and breakfast without TV, related to weight status, sex, level of education, ethnicity and country: parents ( $n$ 6512) of 10-12-year-olds in eight European countries, ENERGY cross-sectional study, 2010

\begin{tabular}{|c|c|c|c|c|c|c|c|c|}
\hline & $n$ & $\begin{array}{c}\text { Underweight } \\
(\%)\end{array}$ & $\begin{array}{c}\text { Normal } \\
\text { weight }(\%)\end{array}$ & $\begin{array}{c}\text { Overweight } \\
(\%)\end{array}$ & $\begin{array}{l}\text { Obese } \\
(\%)\end{array}$ & $\begin{array}{c}\text { Breakfast } \\
\text { skippers (\%) }\end{array}$ & $\begin{array}{c}\text { Breakfast } \\
\text { with TV (\%) }\end{array}$ & $\begin{array}{c}\text { Breakfast } \\
\text { without TV (\%) }\end{array}$ \\
\hline $\begin{array}{l}\text { Total } \\
\text { Underweight } \\
\text { Normal weight } \\
\text { Overweight } \\
\text { Obese } \\
P \text { value }\end{array}$ & $\begin{array}{r}6512 \\
121 \\
3807 \\
1757 \\
585\end{array}$ & 2 & 61 & 28 & 9 & $\begin{array}{l}32 \\
40 \\
29 \\
34 \\
42 \\
\leq 0 \cdot 001\end{array}$ & $\begin{array}{l}23 \\
14 \\
23 \\
23 \\
23 \\
0 \cdot 17\end{array}$ & $\begin{array}{l}44 \\
44 \\
47 \\
42 \\
34 \\
\leq 0.001\end{array}$ \\
\hline $\begin{array}{l}\text { Mother } \\
\text { Father } \\
P \text { value }\end{array}$ & $\begin{array}{l}5308 \\
1109\end{array}$ & $\begin{aligned} & 2 \\
& 0 \\
\leq & 0.001\end{aligned}$ & $\begin{array}{l}66 \\
36 \\
\leq 0 \cdot 001\end{array}$ & $\begin{array}{l}23 \\
50 \\
\leq 0 \cdot 001\end{array}$ & $\begin{array}{l}9 \\
13 \\
\leq 0 \cdot 001\end{array}$ & $\begin{array}{l}31 \\
36 \\
0.006\end{array}$ & $\begin{array}{l}23 \\
23 \\
0 \cdot 70\end{array}$ & $\begin{array}{l}45 \\
40 \\
0 \cdot 005\end{array}$ \\
\hline $\begin{array}{l}\text { Low education } \\
\text { High education } \\
P \text { value }\end{array}$ & $\begin{array}{l}2020 \\
3719\end{array}$ & $\begin{array}{l}2 \\
2 \\
0 \cdot 46\end{array}$ & $\begin{array}{l}57 \\
64 \\
\leq 0.001\end{array}$ & $\begin{array}{l}30 \\
26 \\
0.005\end{array}$ & $\begin{aligned} & 11 \\
& 8 \\
& \leq \\
& 0.001\end{aligned}$ & $\begin{array}{l}42 \\
25 \\
\leq 0 \cdot 001\end{array}$ & $\begin{array}{l}19 \\
25 \\
\leq 0 \cdot 001\end{array}$ & $\begin{array}{l}38 \\
49 \\
\leq 0.001\end{array}$ \\
\hline $\begin{array}{l}\text { Non-native } \\
\text { Native } \\
P \text { value }\end{array}$ & $\begin{array}{l}1108 \\
5307\end{array}$ & $\begin{array}{l}2 \\
2 \\
0 \cdot 93\end{array}$ & $\begin{array}{l}57 \\
62 \\
0.004\end{array}$ & $\begin{array}{l}31 \\
27 \\
0.03\end{array}$ & $\begin{array}{l}11 \\
9 \\
0 \cdot 14\end{array}$ & $\begin{array}{l}38 \\
31 \\
\leq 0.001\end{array}$ & $\begin{array}{l}20 \\
23 \\
0.02\end{array}$ & $\begin{array}{l}40 \\
45 \\
0 \cdot 004\end{array}$ \\
\hline $\begin{array}{l}\text { Belgium } \\
\text { Greece } \\
\text { Hungary } \\
\text { The Netherlands } \\
\text { Norway } \\
\text { Slovenia } \\
\text { Spain } \\
\text { Switzerland } \\
P \text { value }\end{array}$ & $\begin{array}{r}762 \\
1004 \\
929 \\
402 \\
852 \\
1024 \\
962 \\
577\end{array}$ & $\begin{array}{c}2 \\
3 \\
2 \\
1 \\
1 \\
1 \\
2 \\
4 \\
\leq 0 \cdot 001\end{array}$ & $\begin{array}{l}64 \\
51 \\
59 \\
66 \\
61 \\
58 \\
66 \\
68 \\
\leq 0 \cdot 001\end{array}$ & $\begin{array}{l}26 \\
34 \\
26 \\
24 \\
29 \\
32 \\
26 \\
22 \\
\leq 0 \cdot 001\end{array}$ & $\begin{array}{r}8 \\
12 \\
13 \\
10 \\
9 \\
9 \\
6 \\
6 \\
\leq 0 \cdot 001\end{array}$ & $\begin{array}{l}18 \\
54 \\
43 \\
12 \\
16 \\
49 \\
14 \\
34 \\
\leq 0 \cdot 001\end{array}$ & $\begin{array}{l}10 \\
20 \\
15 \\
19 \\
23 \\
9 \\
78 \\
4 \\
\leq 0 \cdot 001\end{array}$ & $\begin{array}{r}72 \\
26 \\
42 \\
69 \\
61 \\
42 \\
5 \\
61 \\
\leq 0 \cdot 001\end{array}$ \\
\hline
\end{tabular}

TV, television; ENERGY, EuropeaN Energy balance Research to prevent excessive weight Gain among Youth. Underweight, $\mathrm{BMI}<18.5 \mathrm{~kg} / \mathrm{m}^{2}$; normal weight, $\mathrm{BMI}=18 \cdot 5-24 \cdot 9 \mathrm{~kg} / \mathrm{m}^{2}$; overweight, $\mathrm{BMI}=25 \cdot 0-29 \cdot 9 \mathrm{~kg} / \mathrm{m}^{2} ; \mathrm{obese}, \mathrm{BMI} \geq 30 \cdot 0 \mathrm{~kg} / \mathrm{m}^{2}$. Proportions are calculated using one-way ANOVA. 
Table 2 Odds ratios and $95 \%$ confidence intervals of being underweight, overweight or obese (compared with normal weight) for breakfast skippers and for breakfast with TV (compared with breakfast without TV), in the total sample and for each country separately: parents ( $n$ 6512) of 10-12-year-olds in eight European countries, ENERGY cross-sectional study, 2010

\begin{tabular}{|c|c|c|c|c|c|c|c|}
\hline & \multicolumn{2}{|c|}{ Underweight } & \multicolumn{2}{|c|}{ Overweight } & \multicolumn{3}{|c|}{ Obese } \\
\hline & OR & $95 \% \mathrm{Cl}$ & OR & $95 \% \mathrm{Cl}$ & OR & & $95 \% \mathrm{Cl}$ \\
\hline \multicolumn{8}{|l|}{ Total } \\
\hline Breakfast skippers & $1 \cdot 4$ & $0 \cdot 9,2 \cdot 2$ & $1 \cdot 2^{*}$ & $1 \cdot 0,1 \cdot 4$ & $1 \cdot 8^{*}$ & & $1 \cdot 5,2 \cdot 3$ \\
\hline Breakfast with TV & $0.5^{\star}$ & $0.2,0 \cdot 9$ & $1 \cdot 1$ & $0 \cdot 9,1 \cdot 3$ & $1 \cdot 4^{*}$ & & $1 \cdot 1,1 \cdot 8$ \\
\hline \multicolumn{8}{|l|}{ Belgium } \\
\hline Breakfast skippers & \multicolumn{2}{|c|}{ NAt } & $0 \cdot 7$ & $0 \cdot 4,1 \cdot 2$ & $1 \cdot 4$ & & $0 \cdot 6,2 \cdot 8$ \\
\hline Breakfast with TV & \multicolumn{2}{|c|}{ NA } & $1 \cdot 0$ & $0.5,1.9$ & $2 \cdot 4^{*}$ & & $1 \cdot 1,5 \cdot 3$ \\
\hline \multicolumn{8}{|l|}{ Greece } \\
\hline Breakfast skippers & $0 \cdot 6$ & $0 \cdot 2,1 \cdot 7$ & 0.9 & $0 \cdot 6,1 \cdot 3$ & $2 \cdot 2^{*}$ & & $1 \cdot 2,4 \cdot 0$ \\
\hline Breakfast with TV & 0.5 & $0 \cdot 1,1 \cdot 9$ & 0.9 & $0.6,1.5$ & $1 \cdot 8$ & & $0.9,3 \cdot 3$ \\
\hline \multicolumn{8}{|l|}{ Hungary } \\
\hline Breakfast skippers & $1 \cdot 8$ & $0 \cdot 6,5 \cdot 4$ & 0.7 & $0 \cdot 5,1 \cdot 1$ & $1 \cdot 7^{\star}$ & & $1 \cdot 1,2 \cdot 8$ \\
\hline Breakfast with TV & \multicolumn{2}{|r|}{ NA } & $1 \cdot 1$ & $0 \cdot 7,1 \cdot 8$ & $1 \cdot 7$ & & $0 \cdot 9,3 \cdot 3$ \\
\hline \multicolumn{8}{|l|}{ The Netherlands } \\
\hline Breakfast skippers & \multicolumn{2}{|r|}{ NA } & $1 \cdot 1$ & $0 \cdot 5,2 \cdot 7$ & \multicolumn{3}{|c|}{ NA } \\
\hline Breakfast with TV & \multicolumn{2}{|r|}{ NA } & $1 \cdot 7$ & $0.9,3.4$ & \multicolumn{3}{|r|}{$1 \cdot 3,7 \cdot 3$} \\
\hline \multicolumn{8}{|l|}{ Norway } \\
\hline Breakfast skippers & \multirow{2}{*}{\multicolumn{2}{|c|}{$\begin{array}{l}\text { NA } \\
\text { NA }\end{array}$}} & $1 \cdot 2$ & $0 \cdot 7,2 \cdot 1$ & \multirow{2}{*}{\multicolumn{2}{|c|}{$\begin{array}{l}1 \cdot 3 \\
1 \cdot 8\end{array}$}} & $0 \cdot 6,2 \cdot 8$ \\
\hline Breakfast with TV & & & $1 \cdot 4$ & $0 \cdot 9,2 \cdot 1$ & & & $1 \cdot 0,3 \cdot 5$ \\
\hline \multicolumn{8}{|l|}{ Slovenia } \\
\hline Breakfast skippers & \multicolumn{2}{|r|}{ NA } & $1 \cdot 6^{\star}$ & $1 \cdot 1,2 \cdot 2$ & \multirow{2}{*}{\multicolumn{2}{|c|}{$\begin{array}{l}1 \cdot 8^{\star} \\
2 \cdot 3^{\star}\end{array}$}} & $1 \cdot 0,3 \cdot 0$ \\
\hline Breakfast with TV & & NA & $1 \cdot 4$ & $0 \cdot 8,2 \cdot 6$ & & & $1 \cdot 0,5 \cdot 3$ \\
\hline \multicolumn{8}{|l|}{ Spain } \\
\hline Breakfast skippers & \multirow{2}{*}{\multicolumn{2}{|c|}{$\begin{array}{l}\text { NA } \\
\text { NA }\end{array}$}} & 0.7 & $0 \cdot 3,1 \cdot 6$ & \multicolumn{3}{|c|}{ NA } \\
\hline Breakfast with TV & & & 0.6 & $0 \cdot 3,1 \cdot 2$ & \multicolumn{3}{|c|}{ NA } \\
\hline \multicolumn{8}{|l|}{ Switzerland } \\
\hline Breakfast skippers & $2 \cdot 7^{\star}$ & $1 \cdot 1,6 \cdot 6$ & $1 \cdot 0$ & $0 \cdot 6,1 \cdot 7$ & $1 \cdot 7$ & & $0 \cdot 8,3 \cdot 6$ \\
\hline Breakfast with TV & \multicolumn{2}{|r|}{ NA } & $1 \cdot 2$ & $0 \cdot 1,3 \cdot 5$ & \multicolumn{3}{|c|}{ NA } \\
\hline
\end{tabular}

TV, television; ENERGY, EuropeaN Energy balance Research to prevent excessive weight Gain among Youth. Underweight, $\mathrm{BMI}<18.5 \mathrm{~kg} / \mathrm{m}^{2} ;$ normal weight, $\mathrm{BMI}=18 \cdot 5-24 \cdot 9 \mathrm{~kg} / \mathrm{m}^{2} ;$ overweight, $\mathrm{BMI}=25 \cdot 0-29 \cdot 9 \mathrm{~kg} / \mathrm{m}^{2} ; \mathrm{obese}, \mathrm{BMI} \geq 30 \cdot 0 \mathrm{~kg} / \mathrm{m}^{2}$. The model is adjusted for sex, ethnicity and level of education as potential confounders. ${ }^{\star} P \leq 0 \cdot 05$.

$\mathrm{TNA}=$ non-applicable due to fewer than five observations in sub-populations.

$1 \cdot 8(95 \%$ CI $1 \cdot 5,2 \cdot 3)$, while no significant association was observed for those being underweight in the total study sample. Significant relationships were also observed within some of the countries; in Greece, the OR of being obese was $2 \cdot 2(95 \%$ CI $1 \cdot 2,4 \cdot 0)$, whereas in Hungary, the OR of being obese was $1 \cdot 7$ (95\% CI 1.1, 2.8). In Slovenia the OR of being overweight was $1.6(95 \%$ CI $1 \cdot 1,2 \cdot 2)$ while the OR of being obese was $1 \cdot 8(95 \%$ CI $1 \cdot 0,3 \cdot 0)$. In Switzerland, the OR of being underweight was $2 \cdot 7(95 \%$ CI 1.1, 6.6). Within the Belgian, Dutch, Norwegian and Spanish samples no significant associations were found for the relationship between weight status and breakfast skipping.

In the total study sample, the OR of being underweight was $0.5(95 \%$ CI $0.2,0.9)$ while the OR of being obese was $1 \cdot 4(95 \%$ CI $1 \cdot 1,1 \cdot 8)$ for breakfast with TV compared with breakfast without TV (Table 2). No significant association was observed for overweight. Similar but sometimes more pronounced and sometimes non-significant results were observed in the separate countries. For example, in the Belgium sample, the OR of being obese was $2 \cdot 4(95 \%$ CI $1 \cdot 1,5 \cdot 3)$ while the OR of being obese was $3 \cdot 1(95 \%$ CI $1 \cdot 3,7 \cdot 3)$ in the Netherlands. In Slovenia the OR of being obese was $2 \cdot 3$ (95\% CI $1 \cdot 0,5 \cdot 3)$. Within the Greek,
Hungarian, Norwegian, Spanish and Swiss samples no significant associations were found for the relationship between weight status and breakfast with TV.

Regarding potential sociodemographic determinants, the OR of being a breakfast skipper was $1 \cdot 4$ (95\% CI $1 \cdot 2$, 1.6) for fathers $v$. mothers, $0.8(95 \%$ CI $0 \cdot 7,1 \cdot 0)$ for natives $v$. non-natives and 0.5 (95\% CI $0 \cdot 4,0 \cdot 5)$ for high educated $v$. low educated, in the full sample (Table 3 ). In the Netherlands, the OR of being a breakfast skipper was $3.8(95 \%$ CI $1.5,9 \cdot 6)$ and $0.2(95 \%$ CI $0 \cdot 1,0.5)$ respectively for fathers and for those highly educated. In both Greece and Hungary, the OR was 0.6 (95\% CI 0.4, 0.9 in Greece; $95 \%$ CI $0.5,0.9$ in Hungary) for parents having high education. In the Norwegian sample, the OR of being a breakfast skipper was $0 \cdot 4(95 \%$ CI $0 \cdot 2,0 \cdot 6)$ for those who were highly educated, while the OR for the same relationship was $0.6(95 \%$ CI $0.5,0 \cdot 8)$ in Slovenia. In Switzerland, the OR of being a breakfast skipper was $0 \cdot 4(95 \%$ CI $0 \cdot 3,0 \cdot 6)$ for high educated $v$. low educated. No significant results were detected for this association in Belgium and Spain.

In the total study sample, as well as in Belgium, Greece, Hungary, Spain and Switzerland, no significant results were found for the relationship between breakfast with 
Table 3 Odds ratios and $95 \%$ confidence intervals for being classified as a breakfast skipper or breakfast with TV (compared with breakfast without TV), according to sex, ethnicity and level of education, in the total sample and for each country separately: parents ( $n$ 6512) of $10-12$-year-olds in eight European countries, ENERGY cross-sectional study, 2010

\begin{tabular}{|c|c|c|c|c|c|}
\hline & \multicolumn{2}{|c|}{ Breakfast skipper } & \multicolumn{3}{|c|}{ Breakfast with TV } \\
\hline & OR & $95 \% \mathrm{Cl}$ & OR & & $95 \% \mathrm{Cl}$ \\
\hline \multicolumn{6}{|l|}{ Total } \\
\hline Sex (father $v$. mother) & $1 \cdot 4^{*}$ & $1 \cdot 2,1 \cdot 6$ & $1 \cdot 2$ & & $1 \cdot 0,1 \cdot 4$ \\
\hline Ethnicity (native $v$. non-native) & $0 \cdot 8^{*}$ & $0 \cdot 7,1 \cdot 0$ & $1 \cdot 2$ & & $1 \cdot 0,1 \cdot 5$ \\
\hline Education (high $v$. low) & $0 \cdot 5^{*}$ & $0.4,0.5$ & $1 \cdot 0$ & & $0 \cdot 8,1 \cdot 1$ \\
\hline \multicolumn{6}{|l|}{ Belgium } \\
\hline Sex (father $v$. mother) & $0 \cdot 6$ & $0 \cdot 3,1 \cdot 3$ & $1 \cdot 2$ & & $0 \cdot 6,2 \cdot 4$ \\
\hline Ethnicity (native $v$. non-native) & $0 \cdot 7$ & $0.3,1.5$ & 0.5 & & $0.2,1 \cdot 1$ \\
\hline Education (high v. low) & $0 \cdot 7$ & $0 \cdot 4,1 \cdot 2$ & $0 \cdot 7$ & & $0 \cdot 4,1 \cdot 4$ \\
\hline \multicolumn{6}{|l|}{ Greece } \\
\hline Sex (father $v$. mother) & $1 \cdot 2$ & $0 \cdot 8,1 \cdot 7$ & $0 \cdot 7$ & & $0 \cdot 4,1 \cdot 2$ \\
\hline Ethnicity (native $v$. non-native) & $1 \cdot 0$ & $0 \cdot 7,1 \cdot 4$ & $0 \cdot 9$ & & $0 \cdot 6,1 \cdot 4$ \\
\hline Education (high $v$. low) & $0 \cdot 6^{\star}$ & $0.4,0.9$ & $0 \cdot 7$ & & $0.5,1 \cdot 1$ \\
\hline \multicolumn{6}{|l|}{ Hungary } \\
\hline Sex (father $v$. mother) & $0 \cdot 8$ & $0 \cdot 5,1 \cdot 3$ & $0 \cdot 9$ & & $0 \cdot 5,1 \cdot 7$ \\
\hline Ethnicity (native $v$. non-native) & $1 \cdot 5$ & $0 \cdot 8,3 \cdot 0$ & \multirow{2}{*}{\multicolumn{2}{|c|}{ NAt }} & \\
\hline Education (high $v$. low) & $0 \cdot 6^{*}$ & $0.5,0.9$ & & & $0 \cdot 5,1 \cdot 2$ \\
\hline \multicolumn{6}{|l|}{ The Netherlands } \\
\hline Sex (father $v$. mother) & $3 \cdot 8^{*}$ & $1 \cdot 5,9 \cdot 6$ & \multicolumn{3}{|c|}{ NA } \\
\hline Ethnicity (native $v$. non-native) & $0 \cdot 8$ & $0 \cdot 3,2 \cdot 0$ & $0 \cdot 8$ & & $0 \cdot 4,1 \cdot 8$ \\
\hline Education (high $v$. low) & $0 \cdot 2^{*}$ & $0 \cdot 1,0 \cdot 5$ & $0 \cdot 3^{*}$ & & $0.2,0.6$ \\
\hline \multicolumn{6}{|l|}{ Norway } \\
\hline Sex (father $v$. mother) & $1 \cdot 4$ & $0 \cdot 8,2 \cdot 4$ & $1 \cdot 0$ & & $0 \cdot 6,1 \cdot 7$ \\
\hline Ethnicity (native $v$. non-native) & $0 \cdot 6$ & $0 \cdot 4,1 \cdot 1$ & $1 \cdot 1$ & & $0 \cdot 7,1 \cdot 9$ \\
\hline Education (high $v$. low) & $0 \cdot 4^{*}$ & $0.2,0.6$ & $0 \cdot 5^{\star}$ & & $0 \cdot 3,0.8$ \\
\hline \multicolumn{6}{|l|}{ Slovenia } \\
\hline Sex (father $v$. mother) & $1 \cdot 4$ & $1 \cdot 0,2 \cdot 0$ & $1 \cdot 7$ & & $0.9,2.9$ \\
\hline Ethnicity (native $v$. non-native) & $1 \cdot 0$ & $0 \cdot 7,1 \cdot 4$ & 0.9 & & $0.5,1 \cdot 6$ \\
\hline Education (high $v$. low) & $0 \cdot 6^{\star}$ & $0.5,0.8$ & $0 \cdot 6^{*}$ & & $0.4,1 \cdot 0$ \\
\hline \multicolumn{6}{|l|}{ Spain } \\
\hline Sex (father $v$. mother) & $1 \cdot 9$ & $0 \cdot 7,5 \cdot 0$ & $1 \cdot 2$ & & $0 \cdot 5,3 \cdot 0$ \\
\hline Ethnicity (native $v$. non-native) & $0 \cdot 6$ & $0 \cdot 2,1 \cdot 8$ & \multirow{2}{*}{\multicolumn{2}{|c|}{ NA }} & \\
\hline Education (high $v$. low) & 0.9 & $0 \cdot 4,2 \cdot 3$ & & & $0 \cdot 6,3 \cdot 1$ \\
\hline \multicolumn{6}{|l|}{ Switzerland } \\
\hline Sex (father $v$. mother) & 1.5 & $0.9,2 \cdot 4$ & $2 \cdot 0$ & & $0 \cdot 8,5 \cdot 2$ \\
\hline Ethnicity (native $v$. non-native) & 0.9 & $0 \cdot 6,1 \cdot 3$ & \multirow{2}{*}{\multicolumn{3}{|c|}{$\begin{array}{l}\text { NA } \\
\text { NA }\end{array}$}} \\
\hline Education (high $v$. low) & $0 \cdot 4^{*}$ & $0.3,0.6$ & & & \\
\hline
\end{tabular}

TV, television; ENERGY, EuropeaN Energy balance Research to prevent excessive weight Gain among Youth. ${ }^{*} P \leq 0.05$.

tNA = non-applicable due to fewer than five observations in sub-populations.

TV and sex, ethnicity and education (Table 3). When looking at separate countries, the following results were noteworthy: in the Netherlands, the OR of breakfast with TV was $0 \cdot 3(95 \%$ CI $0 \cdot 2,0 \cdot 6)$ for parents with more than 14 years of education compared with parents with less education, while the OR for the same relationship was $0.5(95 \%$ CI $0.3,0.8)$ in the Norwegian sample and $0 \cdot 6(95 \%$ CI $0 \cdot 4,1 \cdot 0)$ in Slovenia.

\section{Discussion}

In the total ENERGY cross-sectional study sample, those parents who were categorized as breakfast skippers were significantly more likely to be overweight and obese, while those who were categorized as breakfast with TV were significantly more likely to be obese, compared with breakfast without TV. The present study therefore supports the hypothesis that skipping breakfast and watching TV during breakfast are associated with higher risk of being overweight and obese in adults.

A recent Swedish study on adults reported increased likelihood for overweight and obesity among participants with an irregular meal pattern, in terms of skipping breakfast and lunch and eating late at night ${ }^{(41)}$. Further, previous studies have found an inverse association between breakfast consumption, weight gain and obesity ${ }^{(13-16)}$. However, to our knowledge, no previous studies conducted on adults have assessed the potential implications of watching TV during breakfast, although three experimental studies manipulating TV viewing during lunch and dinner consumption all reported enhanced dietary intake when watching TV regardless of rated appetite ${ }^{(25,34,35)}$. Thus consuming meals in front of the TV might contribute to weight gain over time. Accordingly, observational studies on children have found positive associations between 
frequency of TV watching during meals and both higher BMI and poorer dietary quality ${ }^{(32,33)}$.

As previously described in the literature, the present study also observed significant associations between sex, ethnicity and education (as an indicator of SES) and breakfast skipping. Being a male, non-native and low educated was each associated with skipping breakfast. Clarke $e$ al. ${ }^{(8)}$ reported that white young women showed a positive trend in breakfast frequency between 1984 and 2006, compared with black women and Hispanic women. Further, TV viewing remained constantly higher among minority ethnic groups during the same period, compared with white young adults ${ }^{(8)}$. Accordingly, Merten et al. ${ }^{(15)}$ reported that low-income youth from disadvantaged communities were more likely to skip breakfast. A possible explanation for the gender differences observed in the present study could be that mothers may be more involved in child care in the morning than fathers, making them less likely to be breakfast skippers.

There were noteworthy country differences in the study sample for both the prevalence of breakfast skippers and particularly for eating breakfast with TV. The Spanish excelled in terms of a low rate of breakfast skippers as well as a remarkable high prevalence of breakfast with TV. Switzerland had a low prevalence of breakfast with TV, but more than twice as many Swiss compared with Spanish were categorized as breakfast skippers. Greece, Hungary and Slovenia all had high amounts of breakfast skippers.

The relationship between weight status and breakfast habits differed greatly across countries. The strongest associations between weight status and being a breakfast skipper were observed in Greece and Switzerland, for respectively being obese and underweight. In Greece, breakfast skippers were more than twice as likely to be obese compared with those who ate breakfast without watching TV. In the Swiss sample, breakfast skippers were almost three times as likely to be underweight. In the Netherlands, those categorized as breakfast with TV were more than three times as likely to be obese, compared with breakfast without TV. Regarding associations between breakfast habits and the potential sociodemographic determinants, there were also noteworthy cross-country variations. Significant associations between sex, education and being a breakfast skipper were observed in all countries but Belgium and Spain. In the Netherlands, breakfast skippers were nearly four times more likely to be fathers than to be mothers, and five times less likely to be highly educated. Within the Greek, Hungarian, Norwegian and Slovenian samples those with more than 14 years of education were about half as likely to be breakfast skippers, compared with those with less education. In the relationship between breakfast with TV and sociodemographic characteristics, significant negative associations were observed for those highly educated in the Netherlands, Norway and Slovenia.
Accordingly, Dubois et $a l^{(32)}$ and Coon et $a l^{(6)}$ reported that TV viewing during meals was more common in families with lower socio-economic status, while Rey-López et al. found parental occupation to be inversely associated with TV viewing in adolescents ${ }^{(42)}$.

Important strengths of the present study are the large, multi-national sample allowing unique comparisons across eight European countries, as well as the use of a standardized measurement protocol for data collection and the reliability and validity of the questionnaire measuring the breakfast behaviours. Further, a cross-European investigation of the potential associations between breakfast skipping and watching TV while eating breakfast and weight status among adults has, to our knowledge, not previously been conducted.

However, there are some limitations of our study. Based on the cross-sectional data, we cannot draw any causal inferences. There are also probably several confounding factors related to the association between the selected EBRB and weight status that we have not included and adjusted for in our analyses, such as physical activity, other sedentary behaviours (like total TV viewing), dieting and nutritional habits. Income was not assessed in the questionnaire, although it may be an important SES indicator relative to breakfast skipping. Further, self-reported questionnaires imply a risk for social desirability bias compared with more objective measurements. Potential overestimation of height and under-reporting of weight impairs the validity of the BMI calculation $^{(43)}$, and thus the weight status classifications. Additionally, some countries had a rather low parent participation rate (e.g. the Netherlands and Switzerland), which reduces the validity of the cross-country comparisons. Further, the respondents in the ENERGY sample were mostly female (83\%) and the results may be attributable to the characteristics of our study sample (parents of 10-12-year-olds responding to a questionnaire brought home from school by their child), thus not necessarily generalizable to all European parents. Also, when stratifying on country some of the sub-populations (e.g. those underweight) contained too few observations to do any meaningful comparisons (marked NA in the tables). The cut-off points used for the dichotomous variables classifying breakfast skippers and breakfast with TV also represent a potential weakness, as we lose variance presented in the data material. Future research should address the associations between breakfast skipping, TV viewing at breakfast and weight status both longitudinally and through intervention studies, using standardized objective measurements, in order to draw claims about cause and effect. Additionally, potential implications of TV viewing, as well as other screen activities (i.e. DVD watching, personal computer and games console use), during breakfast and other meals on weight status should be assessed among both children and adults. A more comprehensive knowledge base is needed in order to inform 
future theory- and evidence-based interventions aimed at preventing or reversing the current obesity epidemic.

\section{Conclusion}

Breakfast skippers were significantly more likely to be overweight and obese, and those eating breakfast while watching TV were significantly more likely to be obese and less likely to be underweight. Remarkable country differences were observed within the eight European countries regarding the prevalence of parents skipping breakfast and watching TV during breakfast. Prospective cohort studies and intervention studies are further needed to assess the aetiology of these relationships.

\section{Acknowledgements}

Sources of funding: The ENERGY project is funded by the Seventh Framework Programme (CORDIS FP7) of the European Commission, HEALTH (FP7-HEALTH-2007-B), Grant agreement no. 223254. The content of this article reflects the authors' views only and the European Community is not liable for any use that may be made of the information contained herein. Conflicts of interest: None. Authors' contributions: J.B. developed the concept and design of the ENERGY study. H.B.B. together with E.B. designed the present study. H.B.B. analysed the data and drafted the manuscript. All authors have been involved in the development, coordination and/or implementation of the ENERGY survey. All authors have read and approved the manuscript.

\section{References}

1. World Health Organization (2003) Diet, Nutrition and the Prevention of Chronic Diseases. Joint WHO/FAO Expert Consultation. WHO Technical Report Series no. 916. Geneva: WHO.

2. van der Horst K, Oenema A, van de Looij-Jansen $\mathrm{P}$ et al. (2008) The ENDORSE study: research into environmental determinants of obesity related behaviors in Rotterdam schoolchildren. BMC Public Health 8, 142.

3. Hill JO (2006) Understanding and addressing the epidemic of obesity: an energy balance perspective. Endocr Rev 27, 750-761.

4. van Stralen MM, Velde SJT, Singh AS et al. (2011) EuropeaN Energy balance Research to prevent excessive weight Gain among Youth (ENERGY) project: design and methodology of the ENERGY cross-sectional survey. BMC Public Health 11, 65.

5. Rennie KL, Johnson L \& Jebb SA (2005) Behavioural determinants of obesity. Best Pract Res Clin Endocrinol Metab 19, 343-358.

6. Coon KA, Goldberg J, Rogers BL et al. (2001) Relationships between use of television during meals and children's food consumption patterns. Pediatrics 107, E7.

7. Bowman SA (2006) Television-viewing characteristics of adults: correlations to eating practices and overweight and health status. Prev Chronic Dis 3, A38.
8. Clarke PJ, O'Malley PM, Johnston LD et al. (2009) Differential trends in weight-related health behaviors among American young adults by gender, race/ethnicity, and socioeconomic status: 1984-2006. Am J Public Health 99, 1893-1901.

9. Siega-Riz AM, Popkin BM \& Carson T (2000) Differences in food patterns at breakfast by sociodemographic characteristics among a nationally representative sample of adults in the United States. Prev Med 30, 415-424.

10. Ball K \& Crawford D (2005) Socioeconomic status and weight change in adults: a review. Soc Sci Med 60, 1987-2010.

11. McLaren L (2007) Socioeconomic status and obesity. Epidemiol Rev 29, 29-48.

12. Wang Y \& Beydoun MA (2007) The obesity epidemic in the United States - gender, age, socioeconomic, racial/ethnic, and geographic characteristics: a systematic review and meta-regression analysis. Epidemiol Rev 29, 6-28.

13. Song WO, Chun OK, Obayashi S et al. (2005) Is consumption of breakfast associated with body mass index in US adults? J Am Diet Assoc 105, 1373-1382.

14. Huang CJ, Hu HT, Fan YC et al. (2010) Associations of breakfast skipping with obesity and health-related quality of life: evidence from a national survey in Taiwan. Int $J$ Obes (Lond) 34, 720-725.

15. Merten MJ, Williams AL \& Shriver LH (2009) Breakfast consumption in adolescence and young adulthood: parental presence, community context, and obesity. J Am Diet Assoc 109, 1384-1391.

16. Niemeier HM, Raynor HA, Lloyd-Richardson EE et al. (2006) Fastfood consumption and breakfast skipping: predictors of weight gain from adolescence to adulthood in a nationally representative sample. J Adolesc Health 39, 842-849.

17. Pereira M, Erickson E, McKee P et al. (2011) Breakfast frequency and quality may affect glycemia and appetite in adults and children. J Nutr 141, 163-168.

18. Kant AK, Andon MB, Angelopoulos TJ et al. (2008) Association of breakfast energy density with diet quality and body mass index in American adults: National Health and Nutrition Examination Surveys, 1999-2004. Am J Clin Nutr 88, 1396-1404.

19. Halsey LG, Huber JW, Low T et al. (2012) Does consuming breakfast influence activity levels? An experiment into the effect of breakfast consumption on eating habits and energy expenditure. Public Health Nutr 15, 238-245.

20. Chaput JP, Klingenberg L, Astrup A et al. (2011) Modern sedentary activities promote overconsumption of food in our current obesogenic environment. Obes Rev 12, e12-e20.

21. Williams DM, Raynor HA \& Ciccolo JT (2008) A review of TV viewing and its association with health outcomes in adults. Am J Lifestyle Med 2, 250-259.

22. Foster JA, Gore SA \& West DS (2006) Altering TV viewing habits: an unexplored strategy for adult obesity intervention? Am J Health Behav 30, 3-14.

23. Thorp AA, Owen N, Neuhaus M et al. (2011) Sedentary behaviors and subsequent health outcomes in adults: a systematic review of longitudinal studies, 1996-2011. Am J Prev Med 41, 207-215.

24. Stroebele N \& de Castro JM (2004) Television viewing is associated with an increase in meal frequency in humans. Appetite 42, 111-113.

25. Blass EM, Anderson DR, Kirkorian HL et al. (2006) On the road to obesity: television viewing increases intake of high-density foods. Physiol Behav 88, 597-604.

26. Pearson N \& Biddle SJH (2011) Sedentary behavior and dietary intake in children, adolescents, and adults: a systematic review. Am J Prev Med 41, 178-188. 
27. Wiecha JL, Peterson KE, Ludwig DS et al. (2006) When children eat what they watch - impact of television viewing on dietary intake in youth. Arch Pediatr Adolesc Med 160, 436-442.

28. Scully M, Dixon H \& Wakefield M (2009) Association between commercial television exposure and fast-food consumption among adults. Public Health Nutr 12, 105-110.

29. Martin CK, Coulon SM, Markward N et al. (2009) Association between energy intake and viewing television, distractibility, and memory for advertisements. Am J Clin Nutr 89, 37-44.

30. Rey-López JP, Vicente-Rodriguez G, Ortega FB et al. (2010) Sedentary patterns and media availability in European adolescents: the HELENA study. Prev Med 51, 50-55.

31. Rey-Lopez JP, Vicente-Rodriguez G, Repasy J et al. (2011) Food and drink intake during television viewing in adolescents: the Healthy Lifestyle in Europe by Nutrition in Adolescence (HELENA) study. Public Health Nutr 14, 1563-1569.

32. Dubois L, Farmer A, Girard M et al. (2008) Social factors and television use during meals and snacks is associated with higher BMI among pre-school children. Public Health Nutr 11, 1267-1279.

33. Liang T, Kuhle S \& Veugelers PJ (2009) Nutrition and body weights of Canadian children watching television and eating while watching television. Public Health Nutr 12, $2457-2463$.

34. Hetherington MM, Anderson AS, Norton GNM et al. (2006) Situational effects on meal intake: a comparison of eating alone and eating with others. Physiol Behav 88, 498-505.

35. Bellisle F, Dalix AM \& Slama G (2004) Non food-related environmental stimuli induce increased meal intake in healthy women: comparison of television viewing versus listening to a recorded story in laboratory settings. Appetite 43, 175-180.

36. Higgs S \& Woodward M (2009) Television watching during lunch increases afternoon snack intake of young women. Appetite 52, 39-43.

37. Brug J, Velde SJT, Chinapaw MJM et al. (2010) Evidencebased development of school-based and family-involved prevention of overweight across Europe: the ENERGYproject's design and conceptual framework. BMC Public Health 10, 276

38. Singh A, Chinapaw M, Uijtdewilligen L et al. (2012) Test-retest reliability and construct validity of the ENERGY-parent questionnaire on parenting practices, energy balance-related behaviours and their potential behavioural determinants: the ENERGY-project. BMC Res Notes 5, 434.

39. Statistics Netherlands (2000) Hoe doet het CBS dat nou? Standaarddefinitie allochtonen. Voorburg: Statistics Netherlands.

40. Thomas JR, Nelson JK \& Silverman SJ (2005) Research Methods in Physical Activity, 5th ed. Champaign, IL: Human Kinetics.

41. Berg C, Lappas G, Wolk A et al. (2009) Eating patterns and portion size associated with obesity in a Swedish population. Appetite 52, 21-26.

42. Rey-López JP, Tomas C, Vicente-Rodriguez G et al. (2011) Sedentary behaviours and socio-economic status in Spanish adolescents: the AVENA study. Eur J Public Health 21, 151-157.

43. Larson MR (2000) Social desirability and self-reported weight and height. Int J Obes Relat Metab Disord 24, 663-665. 